\title{
A ergonomia da atividade se interessa pela qualidade de vida no trabalho? Reflexões empíricas e teóricas
}

\author{
Mário César Ferreira \\ Instituto de Psicologia da Universidade de Brasília
}

\begin{abstract}
A relação entre ergonomia da atividade e o campo de intervenção denominado qualidade de vida no trabalho (QVT) não é evidente e, no limite, ausente. Afinal, a ergonomia da atividade se interessa pela qualidade de vida no trabalho? O objetivo deste artigo, de natureza teórica, consiste em repensar essa relação com base em dois eixos: (a) dados empíricos que caracterizam os principais problemas contemporâneos das organizações e que convidam as ciências do trabalho para soluções; e (b) os traços históricos e científicos da ergonomia da atividade que a credenciam para a promoção do bem-estar no trabalho. $O$ ponto de chegada de tais reflexões fornece elementos de resposta à questão inicial, mostrando que tanto os problemas existentes no mundo do trabalho, quanto a tradição científica da ergonomia da atividade convocam os ergonomistas para uma intervenção, de espectro mais largo, no campo da qualidade de vida no trabalho. Isso implica para a disciplina, sem abandonar seus pressupostos epistemológicos, em ampliar seu campo de análise e de contribuições, construindo uma abordagem de QVT de viés preventivo e distinguindo-se da tradição assistencial das práticas de QVT.
\end{abstract}

Palavras-chave: ergonomia, Qualidade de vida no trabalho, QVT.

Is the activity ergonomics interested by the quality work life? Theoretical and empirical reflections

The relation between Activity Ergonomics and the field of intervention named quality of work life (QWL) is not clear and, in the limit, absent. Thus, is the activity ergonomics interested by the quality of work life? The aim of this theoretical-natured article is to rethink this relation based on two axes: (a) empirical data that characterize the main contemporary problems in the organizations and that invite the work sciences to find solutions; and (b) the history and scientific background of the activity ergonomics that enable this field to promote the well-being in the work. The arrival place of such points gives answers elements to the first question, showing that the problems present in the work life and also the scientific tradition of the activity ergonomic call the ergonomists for a wider spectrum intervention in the field of the quality of work life. This implies for the subject, without abandoning its epistemological presuppositions, in enlarging its field of analyses and contributions, building a QWL approach of preventive bias and distinguishing itself from the assistential tradition of QWL practices.

Keywords: Ergonomics, Quality of work life, QWL.

\section{Introdução}

$\mathrm{O}$ objetivo deste artigo é apresentar reflexões, apoiadas em fundamentos empíricos e teóricos, sobre a relação entre a ergonomia e a qualidade de vida no trabalho (QVT). Os fundamentos empíricos baseiam-se tanto em dados contemporâneos do mundo do trabalho, quanto em resultados específicos de estudos e pesquisas em ergonomia. A fundamentação teórica, por sua vez, engloba aspectos históricos, objeto e objetivos da ergonomia.

De entrada, é importante explicitar de qual ergonomia o texto trata, posto que ela se constitui em um campo científico rico e diversificado. As reflexões apóiam-se, essencialmente, na abordagem franco-belga da ergonomia (Wisner, 1994) e sua importante produção científica, a denominada ergonomia da atividade (Montmollin, 1995). A outra grande vertente da ergonomia - de fato, a majoritária em número de integrantes e de 
indicadores bibliográficos -, de filiação anglo-saxônica (human factors) ocupa, de modo residual, a posição de coadjuvante neste texto. Tal recorte visa somente delimitar fronteiras empíricas e teóricas do foco temático do artigo e não enfatizar diferenças epistemológicas dessas duas "escolas" de ergonomia.

À primeira vista, o título deste artigo induziria o leitor a uma resposta afirmativa. Todavia, uma análise da literatura em ergonomia da atividade recomenda certa cautela para responder à questão provocativa que serve de título ao texto. A compreensão de tal cautela interpretativa impõe, portanto, começar argumentando sobre a relevância do objeto do presente artigo. Por que é importante abordar as possibilidades de "diálogo e perspectivas" entre ergonomia da atividade e o campo da qualidade de vida no trabalho? Grosso modo, os motivos são muitos e diversos. Mas, três modalidades reúnem aspectos fundamentais que colocam em primeiro plano a importância desta incursão analítica.

Do ponto de vista social, a relevância se manifesta pelo papel central que o mundo do trabalho assume na vida em sociedade. A centralidade do trabalho e, principalmente, suas implicações econômicas, políticas, tecnológicas e culturais para seus distintos e contraditórios atores (dirigentes, gestores, trabalhadores e usuários/clientes) fundamentam a importância do debate sobre ergonomia e qualidade de vida no trabalho. As metamorfoses que se operam nas organizações públicas e privadas e, sobretudo, os indicadores econômicos e sociais críticos que têm sido produzidos robustecem o desafio de se compatibilizar o bem-estar de quem trabalha e a satisfação de usuários/clientes com os imperativos de eficiência e eficácia nos contextos de produção de mercadorias e serviços. Nesse cenário, a ergonomia pode e tem contribuído para a melhoria dos contextos de trabalho e o tema da qualidade de vida no trabalho, para além da variante modismo, vem se configurando como uma necessidade para eliminar ou atenuar os indicadores críticos existentes (Labiris, Petounis, Kitsos, Aspiotis \& Psillas, 2002; Lau, 2000; Pattanayak, 2003; Steijn, 2001).

Do ponto de vista das organizações, a relevância inscreve-se numa perspectiva de enfrentamento de um elenco de problemas presentes no cotidiano dos ambientes de trabalho que colocam a qualidade de vida no trabalho como uma real necessidade (Laschinger, Finegan, Shamian \& Almost, 2001; Martel \& Dupuis, 2006; Sirgy, Efraty, Siegel \& Lee, 2001). No que concerne às empresas privadas, os desafios postos pela mundialização da economia são inúmeros e cobram respostas "para ontem", merecendo destaque: o novo padrão de competitividade baseada no uso de alta tecnologia e na gestão flexível do trabalho; a atitude mais exigente e proativa de consumidores quanto à relação custo-benefício de produtos e serviços; a evolução da consciência ambiental e a defesa dos recursos naturais. No âmbito do serviço público, dois aspectos caracterizam as transformações: o fortalecimento dos regimes democráticos e, em conseqüência, a postura mais vigilante e reivindicatória dos cidadãos-usuários quanto ao acesso à qualidade dos serviços prestados pelas agências governamentais e por seus dirigentes.

Do ponto de vista acadêmico, a importância deste texto consiste em refletir sobre o papel e o campo de intervenção em ergonomia da atividade em uma perspectiva de problematizar para avançar, ampliar e evoluir a sua abordagem clássica da inter-relação indivíduo-contexto de trabalho, agregando um enfoque (de viés preventivo) de qualidade de vida no trabalho. A tradição dos estudos e das pesquisas em ergonomia da atividade terminou produzindo a "clínica do trabalho" como um de seus traços: diagnóstico do indivíduo (ou de pequenos grupos) em situação de trabalho, mapeando sintomas de disfuncionamentos e prescrevendo recomendações para o reequilíbrio satisfatório da inter-relação indivíduocontexto de trabalho. Olhando o horizonte, sem perder de vista o terreno teórico onde se pisa, vislumbra-se esboçar as bases de um campo novo: a ergonomia da atividade aplicada à qualidade de vida no trabalho (EAAQVT), que vá além da tradição de estudos de casos cuja predominância é a abordagem qualitativa e o mérito indiscutível. 
Isso posto, duas questões servem de "guias" no trajeto argumentativo do presente texto: (a) como se caracteriza o cenário atual de mudanças no mundo do trabalho em termos dos principais indicadores críticos existentes? e (b) quais são os traços característicos principais da ergonomia da atividade que a habilitam para a tarefa da promoção da qualidade de vida no trabalho? A primeira questão é o foco do tópico a seguir.

\section{Cenário de mudanças e principais indicadores críticos no mundo do trabalho}

O cenário contemporâneo do mundo do trabalho, marcadamente em ebulição, tem seu ponto de inflexão histórica no final da década de sessenta do século passado. É naquele período que se iniciava um processo de reestruturação produtiva, ora em curso, como forma de superar a crise vigente no sistema produtivo dos países ocidentais, de feição tayloristafordista (Braverman, 1975). Os aspectos históricos e os traços que foram sendo produzidos pela reestruturação produtiva marcam esse cenário de mudanças.

\section{As marcas das metamorfoses do mundo do trabalho}

$\mathrm{Na}$ década de sessenta, o efeito combinado de diversos fatores (fortalecimento das reivindicações sindicais, esgotamento do enfoque hard da chamada administração científica do trabalho, aumento brutal do preço do petróleo, aumento das taxas de juros) produziu uma crise no modelo de acumulação capitalista, impondo limites concretos nas taxas de mais-valia (Hobsbawm, 1996). Conforme assinala De Toni (2006), instaurou-se:

(...) um processo de reestruturação capitalista que inclui formas diferenciadas de se produzir e organizar o trabalho num contexto de fragmentação e fragilização do movimento sindical. Registram-se a redução do emprego assalariado, especialmente na indústria, a proliferação de atividades em serviços, a expansão de formas atípicas de inserção laboral em frente do padrão assalariado anterior e, principalmente, a ampliação do desemprego e sua manutenção em patamar elevado (p. 127).

Estava nascendo a chamada reestruturação produtiva.

O fenômeno da reestruturação produtiva e industrial pode ser definido como uma busca por harmonizar (compatibilizar) mudanças, principalmente, nos âmbitos do perfil das organizações produtivas, das relações de produção, do modelo dominante de gestão do trabalho, da tecnologia com a introdução de instrumentos de trabalhos baseados na microeletrônica, do papel dos Estados nacionais e do quadro jurídico internacional com medidas voltadas para o fim de barreiras comerciais. $\mathrm{O}$ processo de transição para um novo paradigma produtivo tem sido marcado por diferentes experiências, medidas e enfoques (Mattoso, 1995). A reestruturação da economia mundial, que toma impulso nas décadas de 80 e 90 do século passado, vai paulatinamente dando forma e conteúdo à reestruturação produtiva propriamente dita (Castel, 2003; Leite, 2003; Mattoso \& Baltar, 1996). Nesse sentido, merecem destaque três características principais:

- O primeiro traço marcante consiste no investimento intensivo em inovações tecnológicas, em especial a automação e a informatização do processo de produção de mercadorias e de serviços. Aqui reside, certamente, um dos pilares principais do crescimento contínuo da 
economia sem necessariamente vir acompanhado - e isto é historicamente inédito - da geração de empregos assalariados. O suporte tecnológico da microeletrônica tem produzido mudanças estruturais profundas nas organizações públicas e privadas.

- O segundo traço, o principal deles, situa-se na esfera da gestão organizacional e do trabalho. A introdução de ferramentas informatizadas é um dos facilitadores do enfoque de gestão flexível da produção (fabricação com base na demanda) e do trabalho (gerenciamento mais eficaz do tempo e das performances dos trabalhadores). Sem abandonar os pressupostos da organização científica do trabalho (OCT) de Taylor (radicalizada por Henry Ford), a revolução informacional, com base nos avanços produzidos pela microeletrônica, tem produzido estilos gerenciais diferenciados que, no fundamental, reiteram o papel de coadjuvantes dos trabalhadores nos processos produtivos.

- O terceiro traço importante reside nas iniciativas de mudanças do aparato jurídico que normatiza as relações de trabalho e o próprio processo produtivo. Neste caso, tais iniciativas manifestam-se em dois níveis. O primeiro nível é macro, ou seja, no âmbito dos Estados nacionais e das relações econômicas internacionais. Nesse âmbito trata-se das medidas voltadas para o estabelecimento de bases mais livres para as relações de compra e venda de mercadorias, geração de tecnologias e intensificação do processo de comunicação. O segundo nível é micro, ocorre no interior das próprias organizações por meio do estabelecimento de novas normas, papéis e atribuições aos seus membros, buscando-se acelerar o processo de reestruturação produtiva (como o controvertido banco de horas na gestão da jornada de trabalho).

Nesse cenário de metamorfoses, o paradigma da flexibilização vai se afirmando como um dos pressupostos centrais da chamada reestruturação produtiva (Leite, 1994). A flexibilização pode ser conceituada como uma diretriz de gestão de processos produtivos que busca forjar organizações e trabalhadores resilientes às exigências, cada vez mais complexas (como instabilidade, imprevisibilidade), que resultam das relações de produção e de troca do mundo trabalho. Nessa perspectiva, a tradição do controle normativo das relações de trabalho constitui - parafraseando Drummond - uma "pedra no meio do caminho" da reestruturação produtiva. Entretanto, têm crescido, cada vez mais, os contratos por tempo determinado (causal-workers ou temporary-workers) e os trabalhadores em tempo parcial (part-time-workers). A aplicação do paradigma da flexibilidade vem acompanhada da necessidade de um novo perfil dos trabalhadores (destaque para a polivalência funcional) e da delegação da atividade-meio para fora da empresa (prática da terceirização).

O processo de mudanças aceleradas com base na reestruturação produtiva e apoiada no paradigma da flexibilização está em curso. Mas, seus contornos, conseqüências e tendências apenas começam a se esboçar. Os rumos da reestruturação são ainda incertos. De qualquer forma, as experiências mais eloqüentes e dominantes - em curso nas grandes organizações públicas e privadas - têm revelado seu caráter ideológico. Nesse sentido, a crítica de Sennett (2001) contra o verdadeiro sentido da flexibilização é bastante ilustrativa (grifos nossos):

A palavra "flexibilidade" entrou na língua inglesa no século quinze. Seu sentido derivou originalmente da simples observação de que, embora a árvore se dobrasse ao vento, seus galhos sempre voltavam à posição normal. "Flexibilidade" designa essa capacidade de ceder e recuperar-se da árvore, o teste e restauração de sua forma. Em termos ideais, o comportamento humano flexível deve ter a mesma forca tênsil: ser adaptável às circunstâncias variáveis, mas não quebrado por elas. A sociedade hoje busca meios de destruir os males da rotina com a criação de instituições mais flexíveis. As práticas de flexibilidade, porém, concentram-se mais nas forças que dobram as pessoas (p. 53). 
Essa crítica de Richard Sennett guarda fina sintonia com a crítica, de longa data, da ergonomia da atividade sobre os sistemas produtivos que têm, entre seus pilares de gestão, o pressuposto do trabalhador como variável de ajuste.

É com base nesse cenário que um conjunto de indicadores críticos tem sido produzido e que coloca em primeiro plano a importância e o papel: (a) do resgate da qualidade de vida no trabalho no âmbito das organizações; e (b) da intervenção dos profissionais que atuam no campo das ciências do trabalho.

\section{Indicadores críticos: impactos na produção}

O processo de reestruturação produtiva, até onde se sabe, não tem conseguido sanar efeitos já bem conhecidos do mundo do trabalho os quais já existiam antes mesmo de sua inauguração a partir da década de setenta. Ademais, é preciso registrar que em grande parte das organizações públicas e privadas em países periféricos - como é o caso do Brasil - tal processo ainda permanece marcadamente ausente (Baumgarten, 2006). O velho e carcomido taylorismo-fordismo ainda prevalece como modelo de gestão organizacional e do trabalho.

Não obstante a falta de dados estatísticos mais globais confiáveis sobre indicadores críticos na esfera da produção - o que forneceria uma base de análise com maior grau de confiabilidade - o exame de estudos, pesquisas, relatórios e artigos diversos (inclusive em revistas não especializadas) mostra uma gama de indicadores que aparecem sob a forma de (Pastore, 2001):

- Erros freqüentes na execução de tarefas em virtude, sobretudo, de condições pouco adequadas de trabalho e formação profissional deficiente (por exemplo, aplicativos de computador com usabilidade deficitária que induz aos erros);

- Retrabalho, decorrência inexorável da existência de erros ou falhas de concepção, que impacta na redução da eficácia do processo produtivo, no aumento do custo humano do trabalho e, não raro, repercute na insatisfação de usuários e consumidores;

- Perda e desperdício de material, decorrentes de desenhos de tarefas e processos de trabalho com baixos graus de eficácia e eficiência que, em conseqüência, aumentam os custos de produção, por sua vez, repercutem no preço final das mercadorias (caso do setor privado) e comprometem a qualidade dos serviços públicos prestados aos usuários-contribuintes (caso do setor público);

- Danificação de máquinas e equipamentos que resultam de procedimentos inadequados e, comumente, de produtos oriundos de projetos industriais de concepção deficiente, retardando tempo de produção, aumentando custos, gerando insatisfação, acidentes e doenças entre trabalhadores; e

- Queda e redução da produtividade e da qualidade almejadas de produtos e serviços que impactam na perda de competitividade (no caso do setor privado) e do afastamento da missão maior das agências governamentais de proporcionar o exercício da cidadania aos usuários-contribuintes (caso do setor público).

De modo global, tais indicadores críticos são ilustrativos dos dilemas contemporâneos da produção que inquietam dirigentes e gestores de instituições públicas e privadas. Cabe salientar que esses indicadores se constituem numa espécie de ponta do iceberg, posto que as causas mais profundas e os efeitos em cascata que produzem permanecem pouco conhecidos e estudados. 


\section{Indicadores críticos: impacto sobre os trabalhadores}

Quando os problemas ligados à produção, mencionados anteriormente, tornam-se uma banalidade nas organizações, inexoravelmente eles vêm acompanhados da manifestação de uma série de indicadores críticos relacionados às conseqüências produzidas sobre os trabalhadores. Tais conseqüências se reportam, fundamentalmente, às suas performances nos ambientes de trabalho, suas atitudes/valores e, principalmente, ao estado de saúde. Nesse rol de indicadores críticos sobre os trabalhadores, merecem destaque:

- Absenteísmo crônico que invade o cotidiano de trabalho, superando taxas administráveis e agravando as condições daqueles que permanecem trabalhando em virtude, sobretudo, do aumento da carga de trabalho; paradoxalmente, em muitos casos ausentar-se sistematicamente do trabalho termina funcionando para alguns trabalhadores como estratégia de preservar a própria saúde mental e física;

- Acidentes que crescem sem cessar nas organizações e que produzem uma gama de efeitos nocivos: mutilação de vidas, geração de incapacidades temporárias e permanentes, afastamentos das atividades laborais, aposentadorias precoces; o custo individual, coletivo, social, empresarial e estatal dos acidentes é no caso brasileiro colossal, embora, sua avaliação e medidas necessitem ser aprimoradas;

- Doenças do trabalho e licenças-saúde que se multiplicam e desenham um perfil epidemiológico que fortalece o nexo com os contextos de trabalho nos quais os acometidos estão ou estavam inseridos, merecendo destaque: a epidemia dos distúrbios osteomusculares relacionados ao trabalho (DORT), que se tornou um problema de saúde pública em diversos países ocidentais; e

- Rotatividade de trabalhadores nas organizações privadas que, em virtude do efeito combinado de diversos fatores (por exemplo, precarização das relações e condições de trabalho, baixos salários), transforma os trabalhadores em nômades que perambulam por organizações e estas, por sua vez, fundamentam seus modelos de gestão do trabalho com base na rotatividade sistêmica (o setor de teleatendimento é ilustrativo); um dado, proveniente da Pesquisa Mensal de Emprego do Instituto Brasileiro de Geografia e Estatística (IBGE) no Brasil, mostra que em 2006 cerca de 8,4 milhões de empregados estavam também em busca de um novo emprego em virtude da insatisfação com o emprego atual.

Esse grupo de indicadores críticos reforça uma tese central que nasceu de estudos e pesquisas em ergonomia da atividade (Daniellou, 2004): o paradigma de tratar cada trabalhador como variável de ajuste, sem promover mudanças importantes em diversas esferas do contexto de trabalho (condições, organização, relações socioprofissionais) para regular e implementar estratégias econômicas e empresariais tem limites, pois quando ultrapassam as capacidades humanas geram doenças mentais, físicas e inúmeros casos de suicídios (Valy, 2007). Nesse cenário, o custo humano do trabalho transforma-se predominantemente em produtor de mal-estar, potencializando acidentes e doenças entre trabalhadores.

\section{Indicadores críticos: impactos sobre os usuários e consumidores}

Corolário dos dois grupos anteriores, este grupo de indicadores críticos termina funcionando como uma espécie de desaguadouro dos problemas relativos à produção e aos efeitos nocivos sobre os trabalhadores de ambientes organizacionais igualmente nocivos. $\mathrm{Na}$ linguagem popular, são os usuários dos serviços públicos e os clientes/consumidores de mercadorias e serviços privados que acabam por "pagar o pato". Não é demais lembrar que, neste caso, os trabalhadores podem ser duplamente vítimas, pois fora das organizações são 
eles também usuários e consumidores. Nesse caso, os indicadores críticos mais recorrentes têm se manifestado sobre a forma de:

- Queixas e reclamações da qualidade de serviços e produtos, de cláusulas não cumpridas, dos modos de tratamento recebidos em contextos de atendimento, da falta sequer de acessibilidade aos serviços, em tese, oferecidos. Dois dados empíricos são eloqüentes de tais indicadores críticos: a diversidade de reclamações de usuários e consumidores que aparecem na mídia, estabelecendo rankings de empresas/instituições campeãs de reclamações e a criação de órgãos de defesa dos consumidores que passaram a ter destaque bastante positivo na luta por direitos nas relações de consumo (Alves Júnior, 2005; Freire, 2002; Gonçalves, 2002; Hostensky, 2004);

- Insatisfação de usuários e consumidores quanto à qualidade dos serviços prestados pelo setor público e dos produtos/serviços disponibilizados pelas empresas privadas que prejudica o próprio acesso aos produtos e serviços para satisfazerem suas necessidades individuais e sociais (Menezes, 2003).

Esse conjunto de indicadores globais desenha a criticidade dos problemas mais recorrentes vivenciados em organizações públicas e privadas. No setor privado, ele coloca em risco a tão desejada competitividade, o crescimento sustentável e a fidelização de clientes/consumidores. No setor público, tais indicadores colocam em risco o exercício efetivo da cidadania e, em conseqüência, fragilizam os valores sociais (como a descrença nos dirigentes) e políticos nos regimes democráticos.

Em síntese, buscou-se até aqui esboçar a fundamentação empírica, mais global, que dá sustentação à necessidade de intervenção no campo da qualidade de vida no trabalho. No tópico a seguir são apresentados também fundamentos empíricos, mais específicos, com base nos resultados de pesquisas e estudos em ergonomia da atividade e ciências afins que convocam os profissionais para a urgência de intervenções no campo da qualidade de vida no trabalho. Todavia, a ênfase é na análise dos traços característicos principais da ergonomia da atividade, buscando fornecer os fundamentos teóricos que a habilitam para a tarefa da promoção de QVT.

\section{Os traços característicos da ergonomia da atividade}

Para responder a segunda questão deste texto, o percurso analítico seguirá por aspectos históricos, conceitos de ergonomia, objetos de estudo, alguns dos principais resultados de estudos e pesquisas e elementos teóricos centrais.

\section{Breve histórico: diálogo entre pesquisadores e trabalhadores}

A ergonomia, embora relativamente desconhecida do grande público, tem cerca de meio século de existência. Ela surgiu oficialmente na Inglaterra, ao final da Segunda Guerra Mundial, em 1948, na criação da Research Ergonomics Society. O fato que, segundo os manuais de ergonomia (Iida, 2005; Moraes \& Mont'Alvão, 1998) está na origem da disciplina foi a conseqüência da atuação conjunta de engenheiros, psicólogos e fisiologistas para remodelarem o cockpit dos aviões de caça ingleses. O êxito dessa experiência de natureza interdisciplinar a credenciou para ser exportada para o mundo industrial no pós-guerra.

Assim, surgiu formalmente a ergonomia - "filha da guerra" como assevera Teiger (1993) - cujo estereótipo de "ciência do posto de trabalho" ou, pejorativamente "cadeirologia", permanece forte no imaginário social de leigos. Ocorre que, de início, a 
preocupação da ergonomia estava centrada, segundo Abrahão e Pinho (2002), na “(...) a compreensão das exigências do trabalho, especialmente entre os autores da língua francesa, estava centrada basicamente: a) no gestual; b) no agrupamento das informações; c) nos procedimentos adotados no sistema de produção; e d) nos processos de pensamento" (p. 47). Passado mais de meio século de existência a ergonomia desenvolveu-se teórica e metodologicamente e, hoje, os postos de trabalho são tão-somente um dos objetos de análise da ergonomia.

Ao longo dos anos, a diversidade de práticas em ergonomia deu origem a campos distintos de intervenção (projetos e correção) e de abordagens ou escolas igualmente distintas (human factor engineering e ergonomie de l'activité). Essa distinção não é objeto de consenso na literatura (Iida, 2005). Entretanto, uma análise mais detida coloca em primeiro plano diferenças importantes entre as duas abordagens, em particular no que concerne aos modelos de ser humano e de trabalho que se encontram velados ou explícitos nos diferentes usos que se faz da ergonomia. Nos textos de alguns autores (Sanders \& McCormick, 1987; Tichauer, 1978), o objetivo da ergonomia centra-se primordialmente nos resultados, na produtividade. Nesse sentido, assinala, com justeza, Rozestraten (2005):

É interessante ver como há certa diferença entre a visão européia e a visão norteamericana. Enquanto a primeira coloca em tudo o homem trabalhador em primeiro lugar, a segunda apesar de dizer que "a ênfase é no ser humano" coloca como primeiro objetivo a efetividade e a eficiência do trabalho e o aumento da produtividade. Somente em segundo lugar vêm os "valores humanos" (p. 3).

O enfoque adotado neste texto, conforme assinalado na introdução situa-se, portanto, no campo da ergonomia da atividade. Essa abordagem, de filiação teóricometodológica na produção científica franco-belga (Guérin, Laville, Daniellou, Duraffourg \& Kerguelen, 2001), tem características que, se ampliadas, podem credenciá-la para o enfrentamento da temática qualidade de vida no trabalho no sentido amplo e preventivo dessa noção.

A ergonomia da atividade surgiu na França e na Bélgica na mesma época. Sua história é marcada por forte preocupação social de pesquisadores que habitavam o mundo acadêmico na Europa no século XX. Desde o início, a ergonomia da atividade esteve claramente articulada com o movimento operário, buscando transformar as situações de trabalho e, em conseqüência, atender às demandas sindicais na perspectiva de promover a melhoria das condições de trabalho e garantir a saúde dos trabalhadores.

O fato é que a ergonomia da atividade foi se construindo com base na constatação dos efeitos nocivos produzidos pela administração científica do trabalho, cuja versão mais acabada ao final dos anos 40 tinha a face do taylorismo-fordismo. A jovem ciência propunha uma inversão no paradigma taylorista vigente "one best way" (Bonnardel, 1946): ao invés da adaptação do homem ao trabalho, ela sustenta a necessidade de adaptar, isto sim, o trabalho (sentido largo do termo) a quem trabalha. Nesse sentido, o distanciamento entre as duas perspectivas toma forma e conteúdo (Ferreira, 2004):

(...) abordagem taylorista trabalha implicitamente com o pressuposto da regularidade e estabilidade de funcionamento do operador. Buscando provar que se pode mudar a técnica, os instrumentos, as condiçóes de trabalho numa perspectiva antropocêntrica, a ergonomia opera uma inversão do paradigma homem-trabalho numa perspectiva de adaptar o trabalho ao homem (p. 192).

Eis, portanto, alguns vestígios, de natureza histórica, sobre a origem e o papel da ergonomia da atividade na melhoria do bem-estar dos trabalhadores que apontam na direção de qualidade de vida no trabalho. 


\section{Ergonomia: definições e objeto de estudo}

A revisão de textos clássicos em ergonomia (Daniellou, 2004) mostra que a identidade científica dessa disciplina está em construção. Isso não é por acaso, pois com apenas meio século de existência formal, ela pode ser considerada uma jovem ciência se comparada, por exemplo, com a física. Algumas de suas definições mais recorrentes na literatura colocam em evidência aspectos que interessam aos objetivos deste texto.

A definição pioneira do engenheiro inglês Murrel (1969), um dos fundadores da ergonomia na Europa, começa a desenhar a identidade científica da disciplina (grifos nossos):

Estudo científico da relação entre o homem e seu ambiente de trabalho. Nesse sentido, o termo ambiente não se refere apenas ao contorno ambiental, no qual o homem trabalha, mas também a suas ferramentas, seus métodos de trabalho e à organização deste, considerando-se este homem, tanto como indivíduo quanto como participante de um grupo de trabalho (...). Na periferia da ergonomia (...) estão as relações do homem com seus companheiros de trabalho, seus supervisores, gerente e com sua família (p. 13).

Entretanto, as definições aprovadas em congressos científicos têm sido as mais adotadas na literatura. A definição mais recente, adotada em agosto de 2000, pela Associação Internacional de ergonomia (IEA) é a seguinte (grifos nossos):

A ergonomia (ou o estudo dos fatores humanos) tem por objetivo a compreensão fundamental das interações entre os seres humanos e os outros componentes de um sistema. Ela busca agregar ao processo de concepção teorias, princípios, métodos e informações pertinentes para a melhoria do bem-estar do humano e a eficácia global dos sistemas.

A análise da evolução das definições de ergonomia coloca em evidência algumas de suas características, que autorizam inferir sua importância para uma abordagem de qualidade de vida no trabalho preventiva. Nesse sentido, cabe destacar: (a) o caráter multidisciplinar e aplicado, convocando outros saberes e profissionais para produção de conhecimento sobre um mesmo objeto; (b) o foco no bem-estar dos trabalhadores e na eficácia dos processos produtivos; (c) a adaptação do contexto de trabalho a quem nele trabalha; (d) a transformação dos ambientes de trabalho, buscando conforto e prevenção de agravos à saúde dos trabalhadores. O mais importante: o objeto de estudo, análise e intervenção da ergonomia da atividade é a interação entre os indivíduos e um determinado contexto de trabalho.

Tais características habilitam a ergonomia como uma área científica, mesmo uma "ferramenta", para atuar na temática de qualidade de vida no trabalho. Pode-se depreender que a razão de ser da ergonomia é compreender os problemas (contradições) que obstaculizam a interação (mediação) dos trabalhadores com o ambiente de trabalho, cuja perspectiva é promover o bem-estar de quem trabalha e o alcance dos objetivos organizacionais. Tal horizonte pode ser interpretado como a busca também por qualidade de vida no trabalho.

\section{Alguns dos principais resultados de estudos e pesquisa em ergonomia da atividade}

Um balanço analítico de estudos e de pesquisas em ergonomia, cuja âncora bibliográfica principal encontra-se nos manuais dessa disciplina (Grandjean, 1998; Guérin et al., 2001), permite identificar um conjunto de resultados de análises ergonômicas do trabalho que dão origem ou subsidiam recomendações da disciplina para a melhoria do bem-estar no 
trabalho e a garantia da eficiência e eficácia do processo produtivo. Tais resultados confirmam ou guardam semelhanças com outras descobertas das ciências do trabalho (por exemplo, psicologia, administração, sociologia, psicodinâmica). Entre tais resultados, objeto de relativo consenso entre especialistas, merecem destaque:

a) $\mathrm{O}$ modelo de gestão do trabalho potencializa a ocorrência de mal-estar em trabalhadores e coloca em risco a eficiência e a eficácia duradouras do processo de trabalho quando:

- Inibe ou restringe a autonomia na execução de tarefas, dificultando ou obstaculizando o estabelecimento pessoal de ritmos e cadências e a produção e o uso de savoir-faire;

- Prescreve tarefas fragmentadas e de ciclos curtos;

- Estabelece prazos exíguos para execução de tarefas;

- Impõe controle temporal por parte de chefias, clientes, colegas e, principalmente, de máquinas;

- Induz a aceleração de performances por meio de recompensas monetárias;

- Desenha tarefas com base no pressuposto de "trabalhador médio" que, em conseqüência, não respeita a variabilidade (intra e inter) individual dos trabalhadores, padronizando performances sem considerar adequadamente as capacidades (fisiológicas e psicológicas) e limites de funcionamento do ser humano;

- Estabelece metas, resultados e produtos sem a participação dos interessados e, principalmente, projeta tarefas, situações e produtos com base em modelo simplista ou simplificador de desempenho humano, pois não leva em conta que a ação humana (ainda que no nível do automatismo) pressupõe um mecanismo cognitivo (percepção, tratamento, tomada de decisão, execução, avaliação) que lhe serve de suporte psicológico;

- Projeta situações de trabalho que: (a) não explicitam de modo inequívoco o que se espera do comportamento dos trabalhadores; (b) não avaliam corretamente o estado de saúde dos trabalhadores; (c) não estabelecem, previamente, as atividades de formação e treinamento necessárias; e (d) desconsideram os fatores motivacionais que influenciam a conduta humana;

- Não adéqua os contextos de trabalho ao processo natural de envelhecimento de uma dada população de trabalhadores, dificultando os mecanismos de compensação que nascem - por "efeito idade" - da evolução de competências;

- Dificulta ou impede a cooperação coletiva dos trabalhadores para gestão das exigências sociotécnicas das tarefas e, sobretudo, a construção e operacionalização de estratégias coletivas de superação e compensação dos limites e problemas presentes nas situações de trabalho;

- Busca, de modo inflexível, formatar as performances dos trabalhadores desconsiderando que na atividade humana trabalho há sempre alguma coisa de irredutível a qualquer tipo de previsão e regularidade stricto sensu, pois ela será sempre um compromisso a ser construído a cada momento com base em exigências endógenas (estado funcional momentâneo de cada trabalhador) e exógenas (provenientes do contexto de trabalho); e

- Coloca obstáculos à atividade humana de adaptação à situação real de trabalho, dificultando a mediação entre o que está formalmente estabelecido (prescrito) e as características e exigências concretas de cada situação de trabalho.

b) Os postos de trabalho aumentam os riscos de acidentes e doenças ocupacionais quando não proporcionam, de forma adequada e personalizada, a compatibilidade entre as 
características psicofisiológicas dos usuários, o ambiente físico e social no qual está inserido e as exigências sociotécnicas das tarefas.

c) As condições disponibilizadas para a execução das tarefas aumentam o risco de incidências de distúrbios osteomusculares relacionados ao trabalho (DORT) quando: (a) não proporcionam uma variabilidade postural moderada, em conformidade com as características psicofisiológicas e antropométricas de cada trabalhador; (b) restringem ou impedem a liberdade de escolha de postura apropriada para cada situação; (c) induzem, em conseqüência, à solicitação intensiva de alguns segmentos corporais e respectivas musculaturas.

d) O contexto de trabalho (com todos seus componentes: físicos, instrumentais, sociais, normativos e, em especial, as tarefas prescritas) aumenta consideravelmente o custo humano do trabalho e os riscos de acidentes, doenças, erros e retrabalho quando não incorpora adequadamente e de modo integrado as características singulares de um grupo de trabalhadores em termos de exigências:

- Físicas: estrutura e funcionamento do corpo humano e seus limites em termos de posturas, gestos, deslocamentos, desgaste energético, ciclos circadianos;

- Cognitivas: indissociabilidade entre conhecimento e ação, bem como, os limites neurossensoriais de cada ser humano; e

- Afetivas: produção ininterrupta de significação psíquica e sentimentos de mal e bemestar provenientes da atividade trabalho.

Ao longo de sua história, a produção científica em ergonomia da atividade tem, insistentemente, mostrado que a distância entre o trabalho prescrito e o trabalho real constitui uma descontinuidade fundamental, fundadora de um conflito de duas lógicas: (a) do modelo da realidade em geral e da (b) atividade em particular (Hubault, 1995, 2006). Como distância a ser identificada e analisada, ela é uma fonte produtora de conhecimento em ergonomia. Nesse sentido, estudos e pesquisas (Weill-Fassina, Rabardel \& Dubois, 1993) colocam em evidência o caráter de imprevisibilidade da atividade, pois ela requer a cada instante a inteligência criadora dos trabalhadores.

A atividade não pode, portanto, ser interpretada automaticamente como sinônimo de interesse ou de satisfação no trabalho, posto que os sentimentos de fadiga, monotonia e insatisfação podem estar presentes num mesmo posto de trabalho. Em conseqüência, o foco na análise da atividade em situações reais de trabalho evidenciou o papel estratégico do conhecimento sob a forma de savoir-faire dos trabalhadores, que é construído no dia-a-dia de trabalho para garantir os clássicos imperativos empresariais de produtividade, eficiência e qualidade e, ao mesmo tempo, suas condições de saúde.

Assim, cabe destacar que o foco do olhar teórico-metodológico da ergonomia da atividade está voltado para a singularidade do ato de trabalhar de cada ser humano em contextos assemelhados ou diferentes. Tal singularidade tem múltiplas faces, uma delas talvez a mais relevante - diz respeito à linguagem conforme salienta Motta (1997):

Os seres humanos vivem em um universo de significações. Eles decodificam sem cessar, não apenas as palavras de seus semelhantes, mas também suas expressões, suas posturas, suas ações dos mais variados tipos, sempre lhes atribuindo um sentido. Ocorre da mesma forma com os sentidos que vão assumir suas próprias ações. Essa significação está muito longe de ser universal e está sempre relacionada a uma espécie de linguagem particular (p. 26).

O elenco dos principais resultados de pesquisa, estudos e intervenções em ergonomia e disciplinas afins cumpre, portanto, duas finalidades neste tópico do texto: de um lado, 
complementam os fundamentos empíricos (apresentados acima) que justificam a importância do planejamento e da operacionalização de programas de qualidade de vida no trabalho; e, de outro, destacam aspectos que marcam a identidade da ergonomia da atividade que podem ser úteis para uma abordagem preventiva em QVT.

\section{Traços teóricos distintivos da ergonomia da atividade}

A análise da literatura em ergonomia da atividade, para além dos aspectos mencionados anteriormente, permite identificar alguns de seus principais traços teóricos que marcam sua identidade científica no campo das ciências do trabalho. Tais traços se reportam às dimensões analíticas centrais da ergonomia da atividade e que são conformadores do próprio objeto de investigação sobre o qual repousa sua produção de conhecimentos. Assim, um esforço de síntese aponta para as seguintes dimensões conceituais (Ferreira \& Mendes, 2003):

- Contexto de trabalho: designa o meio físico, instrumental e social onde se realiza a atividade de trabalho. Ele pode ser designado genericamente como um contexto de produção de Bens ou serviços (CPBS), no qual se encontram os parâmetros estruturadores da ação humana. Esses parâmetros manifestam-se, principalmente, sob a forma de informações econômicas ou institucionais, política de pessoal, determinações jurídicas externas, localização espacial, condições de trabalho, organização do processo de trabalho, tarefas prescritas. A compreensão da performance humana é inseparável do diagnóstico dos elementos do CPBS que podem estar na origem, por exemplo, de erros ou acidentes de trabalho.

- Indivíduo: ele assume em ergonomia da atividade contornos singulares, cuja designação já é um distintivo de qual indivíduo se fala: o trabalhador ou a trabalhadora. Em ergonomia da atividade, o indivíduo é sujeito ativo que pensa, age e sente; por meio de sua atividade de trabalho, constrói e reconstrói sua experiência de trabalho cotidianamente. A acepção conceitual distancia-se - a rigor se opõe - das noções de filiação taylorista, de "trabalhador médio" e do "ser humano como variável de ajuste". Nesse sentido, a diversidade e a variabilidade interindividuais (gênero, idade, dimensões corporais, experiência, competências) e intra-individuais (transformações físicas e mentais do próprio trabalhador em função das variações temporais em curto, médio e longo prazos) assumem valor heurístico central na concepção de indivíduo em ergonomia da atividade como fatores fundamentais para se compreender os comportamentos em situação de trabalho.

- Trabalho: comporta dois eixos, cujos sentidos são complementares. Em primeiro lugar, o trabalho assume um sentido macro em função de seu caráter histórico e antropogenético como traço distintivo da espécie humana. Em poucas palavras, o trabalho é, historicamente, o "modo de ser" que possibilitou a espécie a sua acepção humana stricto sensu. Em segundo lugar, o trabalho é ação humana de mediação adaptativa (regulação) por meio do qual os trabalhadores respondem às contradições (problemas, dificuldades, limites, indicadores críticos) existentes nos contextos de trabalho com o objetivo (finalismo) de cumprir as tarefas prescritas e, ao mesmo tempo, garantir o próprio bem-estar. $\mathrm{O}$ trabalho-atividade ocupa lugar epistemológico fundamental no diagnóstico da interação indivíduo-ambiente.

Eis, portanto, as três dimensões fundamentais que caracterizam o "olhar" da ergonomia da atividade sobre o indivíduo em seu contexto de trabalho. Daqui nascem as três questões básicas que, regra geral, norteiam a investigação dessa disciplina na busca de construir quadros elucidativos das mazelas que habitam o mundo do trabalho: Como se caracteriza um dado contexto de trabalho? Como se caracteriza o perfil (demográfico e profissiográfico) dos trabalhadores? Como se caracterizam suas respectivas atividades mediadoras de trabalho? 
Desse modo, a distinção conceitual "contexto de trabalho", "indivíduo" e "atividade" (trabalho) é, antes de tudo, recurso didático de distinção teórica para melhor compreender os elementos básicos que são constitutivos e constituidores do mundo do trabalho. Desenhar cenários explicativos dos problemas encontrados requer fazer, metaforicamente, dois movimentos: um de zoom-in, para examinar exaustivamente cada dimensão analítica e outro de zoom-out, para compreender suas interações e nexo causal com base em uma perspectiva mais holística. É nessa ótica que o título de uma obra de referência clássica em ergonomia da atividade (Guérin et al., 2001) é bastante elucidativo da missão da ergonomia: Compreender o trabalho para transformá-lo: a prática da ergonomia.

Por fim, cabe salientar dois aspectos que permeiam os traços teóricos da ergonomia da atividade e que são essenciais para a interlocução com o campo da qualidade de vida no trabalho.

$O$ primeiro diz respeito à centralidade do enfoque preventivo como diretriz estruturante do diagnóstico ergonômico. A ergonomia da atividade não se ocupa das doenças do trabalho em si mesmas; elas são, a rigor, um "ponto de partida" para a análise ergonômica que é, de fato, seu "ponto de chegada". Seu foco de preocupação, ao diagnosticar as causas dos problemas, é a sua prevenção (por exemplo, acidentes, doenças, erros, retrabalho) nas organizações que colocam em risco o bem-estar dos trabalhadores e a eficiência e eficácia dos processos produtivos.

O segundo se reporta ao seu caráter multidisciplinar que, por natureza, convoca outras ciências e cientistas do trabalho para a parceria na produção de conhecimentos. $\mathrm{O}$ bem-estar no trabalho e o alcance dos objetivos organizacionais, regra geral, não são obras somente de uma ciência ou um cientista isolado, mas fruto de distintas contribuições para elucidar os enigmas que habitam a interação "indivíduo-atividade-contexto de trabalho".

\section{Conclusão}

Afinal, resgatando o título do presente artigo, a ergonomia se interessa pela qualidade de vida no trabalho? Certamente, a resposta é sim. Dois eixos de reflexão foram desenvolvidos ao longo do trajeto argumentativo buscando fornecer elementos de resposta a essa questão-bússola. A título de conclusão é pertinente retomar, sinteticamente, os motivos do sim.

Do ponto de vista empírico, especialistas e pesquisadores que atuam no mundo do trabalho - com destaque para os que adotam a ergonomia da atividade sua abordagem central - têm um cenário macro e micro que os convoca para a ação voltada para a promoção da qualidade de vida no trabalho. Em linhas gerais, o cenário fornece os fundamentos empíricos para a necessidade de QVT com base em dois aspectos principais.

Em primeiro lugar, as aceleradas mudanças no mundo do trabalho são, ao mesmo tempo, causa e conseqüência das transformações que ocorrem para além muros das organizações. Tais mudanças colocam no centro da cena um processo de reestruturação produtiva, cujo suporte principal localiza-se nas inovações tecnológicas (por exemplo, a telemática está permitindo ao dinheiro dar várias voltas ao mundo em nanosegundos) neste limiar do século XXI, que vem buscando instalar um novo paradigma produtivo com base no desenho de um novo perfil para as organizações, a gestão do trabalho e a competência esperada dos trabalhadores. O preceito da flexibilidade como instrumento de gestão, o forte investimento em tecnologias da microeletrônica e a alteração do aparato jurídico são os traços principais do processo de reestruturação produtiva. $\mathrm{O}$ "ponto de chegada" desse 
processo permanece uma incógnita. O sentimento é de que estamos somente entrando no "olho do furacão".

Em segundo lugar, até aqui as práticas dominantes da reestruturação produtiva (nas grandes corporações) revelaram-se ser mais uma modernização conservadora, do tipo neotaylorismo-fordismo. O trabalhador é a variável de ajuste - ele é quem tem que ser flexível e o poder de decisão de quem trabalha cotidianamente permanece restrito, vigiado e, na maior parte dos casos, proibido. Nessa ótica, a reestruturação produtiva tem sido muito mais um obstáculo para o pleno exercício do autêntico sentido do trabalho humano e está na origem da produção e do agravamento de um rol de indicadores críticos que cobrem: a produção de serviços e mercadorias; os efeitos nocivos sobre a saúde dos trabalhadores; e a satisfação de usuários dos serviços públicos e clientes/consumidores do setor privado.

É com base nesse contexto macro e micro conjuntural que a questão da qualidade de vida no trabalho se apresenta como prioridade de agenda de trabalho e intervenção para as ciências do trabalho, em especial para a ergonomia da atividade.

Embora historicamente jovem, a ergonomia da atividade acumulou ao longo de meio século uma experiência analítica dos ambientes de trabalho bastante consistente, que a autoriza a ser uma das protagonistas da promoção da qualidade de vida no trabalho nos cotidianos das organizações. A história da ergonomia da atividade e, sobretudo, os traços que a caracterizam constituem um segundo bloco argumentativo do "sim" para a questão que serve de título deste artigo. Assim, em linhas gerais, o perfil dessa jovem ciência fornece os fundamentos teóricos que a habilitam a estender seu campo de ação, merecendo destaque:

- Do ponto de vista histórico, a ergonomia da atividade tem sua origem marcada pelo envolvimento de pesquisadores com o mundo trabalho na busca, inicialmente, voltada para as condições de trabalho e, com o seu desenvolvimento, passa a englobar de forma evidente as dimensões da organização e das relações socioprofissionais de trabalho. Portanto, o bemestar, a eficiência e eficácia estiveram, desde o início, no centro das preocupações da ergonomia da atividade;

- A definição da ergonomia coloca em primeiro plano seu objeto (interação indivíduoatividade-contexto de trabalho) e seu objetivo de propor, com base em uma perspectiva interdisciplinar, medidas concretas para uma melhor adaptação dos meios tecnológicos de produção e dos ambientes de trabalho e de vida ao homem;

- A consolidação dos principais resultados de estudos, pesquisas e intervenção - muitos oriundos do diálogo com outras disciplinas afins - mostra os fatores principais (modelo de gestão do trabalho, condições de trabalho, custo humano) que potencializam a ocorrência de mal-estar no trabalho e que colocam em risco a saúde dos trabalhadores; tais resultados reforçam os argumentos de natureza empírica sobre a necessidade de qualidade de vida no trabalho em organizações públicas e privadas; e

- Os traços teóricos principais da ergonomia da atividade enfatizam três dimensões analíticas interdependentes: contexto de trabalho, indivíduo e trabalho. Tais dimensões tecem a "tela de fundo" na qual se inscrevem os problemas práticos que são diagnosticados pelos que praticam essa disciplina. O caráter preventivo e a parceria multidisciplinar complementam os traços teóricos da identidade da ergonomia da atividade.

Assim, a ergonomia da atividade, certamente, interessa-se pela qualidade de vida no trabalho. Mas, esse interesse tem contornos específicos. Eles devem, com certeza, distinguirse tanto das abordagens clássicas da quality of work life (Limonge-França, 2003; Hackman \& Oldham, 1975; Walton, 1973), quanto dos enfoques de QVT assistencial, marcados pela exclusividade de práticas anti-estresse e pela natureza compensatória dos desgastes vivenciados no contexto de trabalho (Ferreira, Alves \& Tostes, 2006). Enfoques que, em essência, apóiam-se no pressuposto do trabalhador como variável de ajuste. A ergonomia da 
atividade pode e deve contribuir com a melhoria da qualidade de vida no trabalho, mas com base em outra perspectiva (Ferreira, 2006; Mendes \& Ferreira, 2004). Uma perspectiva de QVT que se apóie em uma abordagem de natureza preventiva, cooperativa com outras ciências do trabalho e seus especialistas e, sobretudo, em uma concepção ontológica do sentido do trabalho que resgaste o seu papel humanizador no âmbito das organizações.

Enfim, a tarefa posta é enriquecer o enfoque tradicional da ergonomia, desenvolvendo uma ergonomia da atividade aplicada à qualidade de vida no trabalho. Isso significa para a ergonomia da atividade avançar na sua história, ampliar seu campo de análise, estender o seu campo de ação e, principalmente, propor mudanças que englobem a organização como um todo. Evidentemente, essa perspectiva tem implicações de natureza metodológica no que concerne à análise ergonômica do trabalho. Isso é um ponto fundamental na agenda para a construção da abordagem: ergonomia da atividade Aplicada à qualidade de vida no trabalho (EAAQVT). Certamente, tal enfoque não pretende ser uma espécie de "panacéia" que resolva todos os problemas vivenciados pelos trabalhadores e gestores, mas uma alternativa que, não obstante seus limites, possa contribuir para as transformações humanizadoras dos contextos de trabalho.

\section{Referências}

Abrahão, J. I. \& Pinho, D. L. M. (2002). As transformações do trabalho e desafios teóricometodológicos da ergonomia. Estudos de Psicologia, 7 (especial), 45-52.

Alves Júnior, R. T. (2005). Avaliação de desempenho, atividade de atendimento ao público e custo humano no trabalho em uma empresa pública no Distrito Federal. Dissertação de Mestrado, Instituto de Psicologia, Universidade de Brasília, Brasília.

Baumgarten, M. (2006). Reestruturação produtiva e industrial. In A. D. Cattani \& L. Holzmann (Orgs.), Dicionário trabalho e tecnologia (pp. 237-239). Porto Alegre: UFRGS.

Bonnardel, R. (1946). A adaptação do homem ao trabalho. Lisboa: Horizonte.

Braverman, H. (1975). Trabalho e capital monopolista: a degradação do trabalho no século XX. Rio de Janeiro: Zahar.

Castel, R. (2003). As metamorfoses da questão social: uma crônica do salário. Petrópolis: Vozes.

Daniellou, F. (Org.). (2004). A ergonomia em busca de seus princípios: debates epistemológicos. São Paulo: Edgard Blücher. (Originalmente publicado em 1996)

De Toni, M. (2006). Fim do trabalho versus centralidade do trabalho. In A. D. Cattani \& L. Holzmann (Orgs.), Dicionário trabalho e tecnologia (pp. 127-131). Porto Alegre: UFRGS.

Ferreira, M. C. (2004). Bem-estar: equilíbrio entre a cultura do trabalho prescrito e a cultura do trabalho real. In A. Tamayo (Org.), Cultura e saúde nas organizações (pp. 181-207). São Paulo: Artmed.

Ferreira, M. C. (2006). Qualidade de vida no trabalho. In A. D. Cattani \& L. Holzmann (Orgs.), Dicionário trabalho e tecnologia (pp. 219-222). Porto Alegre: UFRGS.

Ferreira, M. C. \& Mendes, A. M. (2003). Trabalho e riscos de adoecimento: o caso dos auditores-fiscais da previdência social brasileira. Brasília: LPA.

Ferreira, M. C., Alves, L. \& Tostes, N. (2006). Gestão de qualidade de vida no trabalho (QVT) no serviço público federal: o descompasso entre problemas e práticas gerenciais. Resumos do II Congresso Brasileiro de Psicologia Organizacional e do Trabalho. Brasília: CBPOT. 
Freire, O. N. (2002). "Ser atendente a vida toda é humamente impossível": serviço de teleatendimento e custo humano do trabalho. Dissertação de mestrado, Instituto de Psicologia, Universidade de Brasília, Brasília.

Gonçalves, R. M. (2002). Ergonomia do serviço de atendimento ao público via internet: utilidade e usabilidade de websites para os usuários. Dissertação de Mestrado, Instituto de Psicologia, Universidade de Brasília, Brasília.

Grandjean, E. (1998). Manual de ergonomia: adaptando o trabalho ao homem. Porto Alegre: Artes Médicas.

Guérin, F., Laville, A., Daniellou, F., Duraffourg, J. \& Kerguelen, A. (2001). Compreender o trabalho para transformá-lo: a prática da ergonomia. São Paulo: Edgard Blücher.

Hackman, J. R. \& Oldham, G. R. (1975). Development of the Job Diagnostic Survey. Journal of Applied Psychology, 2 (60), 159-170.

Hobsbawm, E. J. (1996). A era dos extremos: o breve século XX. Rio de Janeiro: Civilização Brasileira.

Hostensky, E. L. (2004). Atendimento ao público interno no Ministério da Educação: três olhares sobre o serviço de saúde prestado aos servidores. Dissertação de Mestrado, Instituto de Psicologia, Universidade de Brasília, Brasília.

Hubault, F. (1995). A quoi sert l'analyse de l'activité en ergonomie. Performances Humaines $\mathcal{E}^{2}$ Techniques, (numéro hors série), 79-85.

Hubault, F. (Org.). (2006). Le stable, l'instable et le changement dans le travail. Toulouse: Éditions Octarès.

Iida, I. (2005). Ergonomia: projeto e produção (2ª ed.). São Paulo: Edgard Blücher.

Labiris, G., Petounis, A., Kitsos, G., Aspiotis, M. \& Psillas, K. (2002). Quality gap, quality of work life and their impact on the performance of an ophthalmologic department. Journal of Medical Marketing, 3 (1), 49-55.

Laschinger, H. K. S., Finegan, J., Shamian, J. \& Almost, J. (2001). Testing Karasek's DemandsControl Model in restructured healthcare settings: effects of job strain on staff nurses' quality of work life. Journal of Nursing Administration, 31 (5), 233-243.

Lau, R. S. M. (2000). Quality of work life and performance: an ad hoc investigation of two key elements in the service profit chain model. International Journal of Service Industry Management, 11 (5), 422-437.

Leite, M. P. (1994). Reestruturação produtiva, novas tecnologias e novas formas de gestão da mão-deobra. In B. C. A. Oliveira (Org.), O mundo do trabalho: crise e mudança ao final do século. São Paulo: Scritta.

Leite, M. P. (2003). Trabalho e sociedade em transformação: mudanças produtivas e atores sociais. São Paulo: Perseu Abramo.

Limonge-França, A. C. (2003). Qualidade de vida no trabalho: conceitos e práticas nas empresas da sociedade pós-industrial. São Paulo: Atlas.

Martel, J. P. \& Dupuis, G. (2006). Quality of work life: theoretical and methodological problems, and presentation of a new model and measuring instrument. Journal Social Indicators Research, 77 (2), 333-368.

Mattoso, J. (1995). A desordem do trabalho. São Paulo: Scritta.

Mattoso, J. \& Baltar, P. E. A. (1996). Transformações estruturais e emprego nos anos 90. Cadernos do Cesit, 21.

Mendes, A. M. \& Ferreira, M. C. (2004). Gestão de pessoas focada na qualidade de vida no trabalho: bem-estar, uma tarefa de todos. Anais do $1^{o}$ Fórum de Qualidade de Vida: Trabalhando e Vivendo com Qualidade (pp. 3-8). Brasília: Banco Central do Brasil. 
Menezes, W. J. (2003). Atendimento presencial em auto-atendimento bancário?!: Um paradoxo à luz das lógicas dos clientes, dos atendentes e dos gestores. Dissertação de Mestrado, Instituto de Psicologia, Universidade de Brasília, Brasília.

Montmollin, M. (1995). A ergonomia. Lisboa: Instituto Piaget.

Moraes, A. \& Mont'Alvão, C. (1998). Ergonomia: conceitos e aplicações. Rio de Janeiro: 2AB.

Motta, F. P. (1997). Cultura e organizações no Brasil. In F. P. Motta \& M. P. Caldas (Orgs.), Cultura organizacional e cultura brasileira (pp. 25-37). São Paulo: Atlas.

Murrel, K. F. H. (1969). Ergonomics, man in his working environment. London: Chapman \& Hall.

Pastore, J. (2001, 21 de março). O custo dos acidentes de trabalho. Jornal da Tarde, São Paulo.

Pattanayak, B. (2003). Towards building a better HRD climate: a study on organisational role stress and quality of work life. International Journal of Human Resources Development and Management, 3 (4), 371-378.

Rozestraten, R. J. A. (2005). Ergonomia no trânsito. Psicologia: Pesquisa $\mathcal{G}$ Trânsito, 1 (1), 1-8.

Sanders, M. S. \& McCormick, E. J. (1987). Human factors engineering and design. Berkeley: University of California Press.

Sennett, R. (2001). A corrosão do caráter: conseqüências pessoais do trabalho no novo capitalismo. Rio de Janeiro: Record.

Sirgy, M. J., Efraty, D., Siegel, P. \& Lee, D. (2001). A new measure of quality of work life (QWL) based on need satisfaction and spillover theories. Journal Social Indicators Research, 55 (3), 241-302.

Steijn, B. (2001). Work systems, quality of working life and attitudes of workers: an empirical study towards the effects of team and non-teamwork. New Technology, Work and Employment, 16 (3), 191-203.

Teiger, C. (1993). L'approche ergonomique: du travail humain à l'activité des hommes et des femmes au travail. Education Permanente, 116, 71-96.

Tichauer, E. R. (1978). The biomechanical basis of ergonomics: anatomy applied to the design of work situations. New York: John Wiley \& Sons.

Valy, C. (2007, 4 de maio). Renault: un suicide qualifié d'accident du travail. Le Monde.

Walton, R. E. (1973). Quality of work life: what is it? Sloan Management Review, 1 (15), 11-21.

Weill-Fassina, A., Rabardel, P. \& Dubois, D. (1993). Représentations pour l'action. Toulouse: Éditions Octarès.

Wisner, A. (1994). A inteligência no trabalho: textos selecionados de ergonomia. São Paulo: Ministério do Trabalho e Fundacentro.

\section{Endereço para correspondência:}

mcesar@unb.br, mario.cesar@pq.cnpq.br 